\title{
PENGARUH KARAKTERISTIK ORGANISASI TERHADAP PEMANFAATAN POS PEMBINAAN TERPADU PENYAKIT TIDAK MENULAR (POSBINDU PTM) DI WILAYAH PUSKESMAS HELVETIA MEDAN
}

Riri Astika Indriani*, Zulfendri**, Surya Utama** [S2 AKK FKM USU*, Departemen AKK FKM USU**]

\section{AIM / OBJECTIVE}

Penyakit tidak menular (PTM) menjadi penyebab utama kematian secara global. Data WHO menunjukkan bahwa dari 56,4 juta kematian yang terjadi di dunia pada tahun 2015, sebanyak 39,5 juta kematian atau hampir $70 \%$ disebabkan oleh PTM (WHO, 2015).

Posbindu PTM menjadi salah satu strategi penting dalam mengendalikan trend penyakit tidak menular yang terus meningkat. Puskesmas Helvetia merupakan salah satu puskesmas di Kota Medan dengan persentase kelurahan yang menjalankan Posbindu PTM terendah yaitu sebesar 28,57\%. Pada tahun 2016, cakupan kegiatan Posbindu PTM di wilayah Puskesmas Helvetia sangat rendah yaitu dibawah $1 \%$.

Tujuan penelitian adalah untuk menganalisis pengaruh karakteristik organisasi (perilaku petugas kesehatan, perilaku kader, fasilitas pelayanan, kegiatan Posbindu PTM) terhadap pemanfaatan POSBINDU PTM di wilayah Puskesmas Helvetia.

METHODS

Jenis penelitian adalah penelitian survai mempunyai kontribusi yang paling besar dengan tipe explanatory research. Penelitian $(B=0,636)$ terhadap pemanfaatan POSBINDU dilaksanakan di Kelurahan Helvetia Tengah dan PTM. Kontribusi ketiga variabel tersebut Helvetia Timur Kecamatan Medan Helvetia Kota terhadap pemanfaatan Posbindu PTM adalah Medan. Populasi dalam penelitian ini adalah sebesar $91 \%$.

masyarakat berusia 15 tahun keatas. Teknik

pengambilan sampel secara proportionate stratified random sampling sebanyak 100 orang. Data primer diperoleh melalui wawancara langsung dengan menggunakan kuesioner. Data dianalisis dengan uji regresi linear berganda.

\section{RESULTS}

Secara umum perilaku petugas kesehatan berada pada kategori buruk (47\%), perilaku kader berada pada kategori buruk (47\%), fasilitas pelayanan berada pada kategori sedang (55\%) dan kegiatan Posbindu PTM berada pada kategori buruk $(44 \%)$

\section{CONCLUSIONS}

Disarankan

dalam Posbindu PTM agar meningkatkan advokasi dan sosialisasi Posbindu PTM, meningkatkan kerjasama dengan lintas sektor terkait, mengganti kader yang tidak aktif, melatih kader Posbindu PTM melengkapi sarana dan prasarana Posbindu PTM sesuai standard, membentuk Posbindu PTM disetiap

Tingkat pemanfaatan Posbindu PTM oleh responden secara umum berada dalam kategori rendah yaitu sebesar $63 \%$, kategori sedang sebesar $28 \%$ dan kategori tinggi memanfaatkan pelayanan Posbindu PTM sebesar 9\%.

Perilaku petugas kesehatan ( $p$ value= $0,000)$, perilaku kader $(p$ value $=0,000)$ dan fasilitas pelayanan ( $p$ value $=0,000$ ) berpengaruh terhadap pemanfaatan Posbindu PTM sedangkan kegiatan Posbindu PTM ( $p$ value $=$ 0,413 ) tidak berpengaruh terhadap pemanfaatan Posbindu PTM. Posbindu PTM.
Diperkirakan perilaku petugas kesehatan

\section{BIBLIOGRAPHY}

Annisa, Nina, 2016, Analisis Pelaksanaan Program Pos Pembinaan Terpadu Penyakit Tidak Menular di Wilayah Kerja Puskesmas Polonia Kecamatan Medan Polonia Tahun 2016, Skripsi, Medan: Fakultas Kesehatan Masyaraka Universitas Sumatera Utara.

Astuti, Emi Dwi, Prasetyowati, Irma, Ariyanto, Yunus, 2016 Gambaran Proses Kegiatan Pos Pembinaan Terpadu Penyaki Tidak Menular di Puskesmas Sempu Kabupaten Banyuwangi, eJurnal Pustaka Kesehatan, 4(1)

Dever,A, 1984, Epidemiology in Health Services Management Uniced Stated Of America: An Aspen Systems Corporation.

. Medan Tahun 2016.

Fauzia, 2013, Analisis Pemanfaatan Pos Pembinaan Terpad Knyakt Tidak Menular di Wlayah Puskesmas Warung Jambu Kota Bogor Tahun 2013, Tesis, Jakarta: Fakultas Kesehatan Masyarakat Universitas Indonesia.

Kementrian Kesehatan RI, 2012, Petunjuk Teknis Pos Pembinaan Terpadu Penyakit Tidak Menular (POSBINDU PTM).

wilayah kerja Puskesmas Kiting, Renate Pah, IImi, Bahrul, Arifin, Syamsul, 2015, Faktor Helvetia, melakukan monitoring dan Yang Berhubungan dengan Kinerja Kader Posbindu Penyakit evaluasi kegiatan Posbindu PTM secara Notoatmodjo, Soekidjo, 2012, Promosi Kesehatan \& Ilmu Perilaku, berkala serta pemerintah daerah Jakarta: Rineka Cipta

diharapkan memberikan dukungan dana Purdiyani, Fauzia, 2016, Pemanfaatan Pos Pembinaan Terpadu : Penyakit Tidak Menular (POSBINDU PTM) Oleh Wanita Lansia

$\begin{array}{ll:l}\text { menunjang keberlangsungan } & \text { Dalam Rangka Mencegah Penyakit Tidak Menular di Wilayah } \\ \text { Kerja Puskesmas Cilongok 1, Jurnal Kesehatan Masyarakat (e- }\end{array}$ Journal), 4(1)

Umayana, Hantek Try, Cahyati, Widya Hary, 2015, Dukungan Keluarga dan Tokoh Masyarakat Terhadap Keaktifan Penduduk ke Posbindu Penyakit Tidak Menular, JurnalKemas 11(1):96-101. WHO Noncommunicable diseases (NCD), diunduh di 